\title{
Of Epiphytes and Epilepsy
}

Lealani Mae Acosta, MD, MPH(D)

Vanderbilt University Medical Center, Nashville, TN, USA.

$I^{2}$

had a succulent hanging from my office cabinet: nestled in a mound of fake snow, illuminated by fairy lights, dangling in a glass teardrop-shaped terrarium, swinging by jute twine.

$\mathrm{He}$

has Trisomy 21 and Alzheimer's disease, his gift his friendly smile.

Once he had a goatee, betraying ginger roots

previously concealed by a thinning pate and favorite baseball caps.

He eventually shaved it off,

much to the relief of his sister, who always accompanied him.

She

flipped a switch at the bottom, an electric cloud of twinkle lights

floating above the snowy white flakes and pointed green arches.

I

saw him in the emergency department, myoclonic jerks raising his arms, almost a celebratory gesture, every few minutes.

His sister, bedside as his entire body shuddered and danced. I

was a doubting Thomas, reluctant to acquiesce to vague secondhand reports from outside hospitals until I touched for myself his convulsing hands and feet.

She

held his hand. EEG confirmed.

The anti-epileptic we'd been blaming and weaning slowly for months, that seeming agitator, irritator, eclipsing his sweet-natured disposition,

now hero.

I

had been tasked to bring something beautiful to a work meeting,

so I cupped the glass terrarium in the middle console of my car, When a backpack fell the teardrop shattered rupture in the employee garage.

It

longer dangles from the jute twine;

the succulent sits squat and proud on my desk.

The jagged edges outline where once was clear dome.

Fairy lights still twinkle on or off with the touch of a switch.

bemoan being all thumbs; contemplate healer's hands.

$\mathrm{He}$

remains seizure free.

J Gen Intern Med 36(7):2149

DOI: $10.1007 /$ s11606-021-06826-1

(c) Society of General Internal Medicine 2021

Corresponding Author: Lealani Mae Acosta, MD, MPH, Vanderbilt University Medical Center, Nashville, TN, USA

(e-mail: lealani.mae.acosta@vumc.org).

Publisher's Note: Springer Nature remains neutral with regard to jurisdictional claims in published maps and institutional affiliations.

Received August 14, 2020

Accepted April 11, 2021

Published online May 5, 2021 